Dossiê: Desafios teológicos do Pluralismo Religioso - Artigo original (9) $\odot$

\title{
Pluralismo religioso, direitos humanos e democracia
}

\author{
Religious pluralism, human rights and democracy
}

\author{
Cláudio de Oliveira Ribeiro*
}

\begin{abstract}
Resumo
Apresenta os resultados de pesquisa realizada em torno de questões que emergem do quadro de pluralismo religioso e se relacionam com a temática da defesa dos direitos humanos e com aspectos em torno dos processos de aprofundamento da democracia. Metodologicamente, foi priorizado, em um primeiro momento, um balanço de questões que demarcam o caminho para uma teologia ecumênica das religiões, pois elas geram novas perspectivas teológicas para os temas tratados. Em seguida, destacamos (i) aspectos da tendência atual dos processos de privatização das experiências religiosas, com a premissa de que tais aspectos não favorecem a relação religião e direitos humanos, e (ii) as relações entre teologia ecumênica e direitos humanos, privilegiando o diálogo com a noção de globalização contra-hegemônica, de Boaventura de Souza Santos. Entre os resultados da pesquisa, destacamos bases teóricas que mostram que faz-se necessária para a teologia das religiões uma atenção especial à articulação entre a capacidade de diálogo dos grupos religiosos e os desafios em torno da defesa dos direitos humanos. Também indicamos que uma espiritualidade ecumênica que emerge do pluralismo religioso terá como valor a dimensão de alteridade e isso incidirá nos processos religiosos e sociais, favorecendo perspectivas utópicas, democráticas e doadoras de sentido.
\end{abstract}

Palavras-chave: pluralismo religioso; teologia ecumênica das religiões; direitos humanos, democracia.

\begin{abstract}
This paper introduces the results of a research on questions raised up by religious pluralism related to the promotion of human rights, and some aspects around the deepening of democracy. Methodologically, we first focused on the balance of some important questions for ecumenical theology of religions, because they raise new theological perspectives. Then, we highlighted (i) some aspects of the contemporary tendency to privatize religious experiences, all of this as impediment to a good balance between religion and human rights. (ii) We analyzed the relationship between ecumenical theology and human rights, in a dialogue with Boaventura de Souza Santo's 'counter-hegemonic globalization' concept. In front of religious pluralism it is necessary to give special attention to the articulation between the capability of religious groups to dialogue and the challenges around the promotion of human rights. We also indicate that an ecumenical spirituality emerging from religious pluralism will have alterity as a central dimension, and this will have a direct impact in religious and social processes giving birth to utopian and democratic meaningful perspectives.
\end{abstract}

Keywords: religious pluralism; ecumenical theology of religions; human rights; democracy.

Artigo recebido em 29 de maio de 2014 e aprovado em 17 de março de 2015.

*Doutor em Teologia pela PUC- RJ. Professor titular de Teologia e Ciências da Religião da Universidade Metodista de São Paulo. País de Origem: Brasil. E mail: claudio.ribeiro@metodista.br

Horizonte, Belo Horizonte, vol. 13, n. 40, p. 1805-1825, out./dez. - ISSN 2175-5841 


\section{Introdução}

Nos últimos anos tenho procurado pesquisar sobre o tema do pluralismo religioso, dentro de um enfoque teológico. De tantas e variadas temáticas e questões que o debate em torno do pluralismo religioso suscita, uma que tem sido destaque e requer um aprofundamento teórico é em que grau a consideração do pluralismo religioso como valor, ou pluralismo de princípio, como é chamado por alguns, favorece o aprofundamento da democracia e fortalece os espaços de defesa dos direitos humanos.

Tal pergunta se coloca, entre outras razões, pelo fato de precisarmos aternos a um questionamento corrente: a atual valorização do pluralismo religioso não se dá concomitantemente à perda de força política e social das religiões? Na mesma direção, questiona-se se a valorização do pluralismo religioso não seria uma forma de ocultar a perda de significado social da religião na atualidade.

É fato que as experiências religiosas na atual sociedade globalizada apresentam-se fortemente influenciadas pelo modelo econômico vigente. Por isso, reconhecemos que as análises científicas da religião não podem prescindir da relação com a economia, especialmente a força sedutora do capitalismo globalizado, como força de massificação e uniformização dentro de um quadro crescente de diversidade religiosa. Evidencia-se cada vez mais a privatização da experiência posta no indivíduo como sujeito autônomo da sua fé, capaz de escolher dentre as ofertas do mercado religioso os aspectos que lhe agradam e que contribuem para a recomposição de seu mundo e integrá-los em uma variada coloração religiosa. Há também as teses que, seguindo Walter Benjamin (2103), defendem a ideia da força do sistema capitalista como religião (LÖWY, 200o, HINKELAMMERT, 2012), subtraindo dela a importância na organização da vida. No entanto, nossa pressuposição é que, não obstante esses dois fatores, as religiões vivem e assentam suas práticas e perspectivas teológicas no "turbilhão" conflitivo das forças hegemônicas imperiais na sociedade, em tensão permanente com os 
processos contra-hegemônicos que visam ao aprofundamento da democracia para além dos aspectos formais e à defesa radical dos direitos humanos.

No cruzamento da importância pública das religiões com a força dos movimentos contra-hegemônicos na sociedade, em boa parte associados direta ou indiretamente a movimentos religiosos, reforça-se o interesse pelo pluralismo religioso entendido como valor e pelos esforços de diálogos inter-religiosos em seus diferentes níveis.

Nesta análise, priorizaremos um primeiro bloco com um balanço das questões que demarcam o caminho para uma teologia ecumênica das religiões, pois as temáticas da defesa dos direitos humanos e da democracia são fruto de tais questões.

Em seguida, entrando mais propriamente na temática proposta, destacaremos aspectos da tendência atual dos processos de privatização das experiências religiosas. Nossa argumentação está assentada na premissa de que tais aspectos, devido ao reforço ao individualismo e à quase ausência de ênfase na solidariedade humana e na sensibilidade comunitária e coletiva para as questões sociais, não favorecem a relação entre experiência religiosa e a luta pelos direitos humanos.

Em um terceiro momento, analisaremos as relações entre teologia ecumênica e direitos humanos, dialogando com a noção de globalização contrahegemônica, de Boaventura de Souza Santos, esboçada em sua obra Se Deus Fosse um Ativista dos Direitos Humanos (2013). Consideramos que o tema da emancipação humana se articula frontalmente com as questões teológicas em torno da democracia.

A linha que costura as questões propostas se baseia na ideia de que os ajustes sociais e econômicos implementados pelas políticas hegemônicas têm gerado degradação humana, perda do sentido de dignidade e consequentes 
problemas sociais das mais variadas naturezas, atingindo os setores e as pessoas mais pobres da sociedade. Além disso, contraditoriamente, em meio ao processo de globalização da economia e da informação, emergem, com maior intensidade, os conflitos étnicos, raciais, sexuais e regionais no mundo inteiro.

\section{0 caminho percorrido em direção à teologia ecumênica das religiões}

Seguindo as trilhas da tradição teológica latino-americana, nossa primeira preocupação na pesquisa foi 'olhar' as realidades de pluralismo religioso, especialmente a do Brasil. Nossas análises procuraram identificar os aspectos do quadro religioso brasileiro atual que consideramos os mais importantes para uma compreensão das possibilidades e dos limites do pluralismo religioso. Entre tais aspectos estão: (i) a relação das características do pluralismo religioso atual com a matriz religiosa e cultural brasileira, marcada por elementos mágicos e místicos, fruto de uma simbiose das religiões indígenas, africanas e do catolicismo ibérico; (ii) os processos de privatização das experiências religiosas, especialmente, como o fator econômico intervém na religião; (iii) os processos de secularização e as novas formas religiosas, incluindo as formas de trânsito religioso e o lugar das mídias no processo religioso; e (iv) a relação entre as expressões de fundamentalismo e as de pluralismo (RIBEIRO, 2014).

O segundo passo dado em nossas análises foi o de rever as tipologias de uma teologia ecumênica das religiões. Consideramos que a vocação ecumênica, ao marcar as reflexões teológicas e pastorais, revela que o caráter de apologia, de sectarismo ou de exclusivismo é ou deve ser evitado. Deus é sempre maior do que qualquer compreensão ou realidade humana. Age livremente, em especial na ação salvífica. Nesse sentido, não é preciso estar excessivamente preocupado em descobrir quem é ou será salvo (para utilizar o imaginário comum dos cristãos); mas quem é e o que representa Jesus Cristo para a comunidade cristã. Essa perspectiva nos remete à busca de um novo paradigma para a teologia das religiões. Trata-se da superação dos seguintes modelos: o que considera Jesus Cristo e a 
Igreja como caminho necessário para a salvação (exclusivismo); o que considera Jesus Cristo como caminho de salvação para todos, ainda que implicitamente (inclusivismo); e aquele no qual Jesus é o caminho para os cristãos, enquanto para os outros o caminho é a sua própria tradição, sem maiores esforços de autocríticas, revisões e mútua interpelação (relativismo). A perspectiva pluralista, que advogamos, possui como característica básica a noção de que cada religião tem a sua proposta salvífica e de fé que deve ser aceita, respeitada e aprimorada a partir de um diálogo e aproximação mútua. Assim, a fé cristã, por exemplo, necessita ser reinterpretada a partir do confronto dialógico e criativo com as demais fés. O mesmo deve se dar com toda e qualquer tradição religiosa. Tal perspectiva não anula nem diminui o valor das identidades religiosas - no caso da fé cristã, a importância de Cristo -, mas as leva a um aprofundamento e amadurecimento, movidos pelo diálogo e pela confrontação justa, amável e corresponsável.

Um terceiro passo foi apresentar um elenco de questões que fundamentam e justificam uma aproximação ecumênica entre as religiões. Trata das possibilidades de uma teologia ecumênica das religiões, tendo como eixo articulador a preocupação pela paz, pela justiça e pela integridade da criação. Com isso, a partir da contribuição de renomados autores, analisamos temas de destaque para o cenário das análises sociais e teológicas, como o valor do humano e da ética social para o diálogo inter-religioso; as possibilidades de uma unidade aberta, convidativa e integradora no âmbito das religiões; a importância pública das religiões; as religiões como códigos de comunicação; e a relação entre o poder do império e o poder do diálogo das religiões, e como ele influi na defesa dos direitos humanos e no aprofundamento da democracia e como redimensiona a missão cristã.

Um quarto passo dado foi e é igualmente desafiador, pois, considerando o contexto da fé cristã desafiada pelo pluralismo religioso, trata da questão cristológica. Apresentamos uma perspectiva cristológica plural na relação interreligiosa, a partir da visão de que cada expressão religiosa tem a sua proposta 
salvífica e que elas poderão ser melhor interpretadas, conhecidas e vivenciadas no contexto de alteridade, de aproximação e de diálogo. Na visão pluralista cristã, realça-se a concepção de "Jesus como símbolo de Deus", expressão consagrada pelo teólogo Roger Haight e que se tornou título de um dos seus livros (2003). Nela, os elementos-chaves da vivência religiosa e humana em geral são alteridade, respeito à diferença e diálogo e cooperação prática e ética em torno da busca da justiça e do bem-comum. A aproximação e o diálogo entre grupos de distintas expressões religiosas cooperam para que elas possam construir ou reconstruir suas identidades e princípios fundantes.

Um quinto passo, igualmente importante e desafiador, foi a relação entre missão cristã e diálogo inter-religioso. O tema da missão é algo crucial na prática da fé cristã e que tem sido analisado e reinterpretado diante do horizonte de uma cultura religiosamente plural. Trata-se de tema desafiador, pois a perspectiva do diálogo pode ser interpretada em diferentes sentidos, incluindo o receio pela perda da identidade religiosa e da assimilação de práticas sincréticas e também o temor em relação ao fato da missão ser inviabilizada pelo diálogo inter-religioso. Daí ser fundamental refletirmos sobre ele no contexto da teologia ecumênica das religiões. A perspectiva do diálogo leva os grupos cristãos a repensarem a missão que se centrou em um mero exercício de tentar convencer as pessoas com crenças distintas ao cristianismo para se converterem à religião cristã e aos seus princípios e crenças tradicionalmente construídas. No espaço do diálogo, as tradições religiosas interpelaram-se, levando as suas vivências para caminhos mais profundos. Trata-se de uma abertura para a escuta, para a mudança e para uma maior compreensão do próprio espaço de fé. Pois, no diálogo há uma mudança e a criação de um lugar fértil para a espiritualidade missionária. Tal perspectiva corrobora com os processos de formação cultural com acento democrático.

O último passo - e esse é o que tem norteado nossas reflexões - trata da apresentação de desafios que a pluralidade religiosa traz para a teologia latinoamericana. Como resultado dessa perspectiva, formulamos três eixos norteadores 
da temática: a) A importância pública das religiões para os processos de promoção da paz e da justiça, associada ao valor da mística e da alteridade na formação de espiritualidades ecumênicas e como elas incidirão nos processos religiosos e sociais, favorecendo perspectivas utópicas, democráticas e doadoras de sentido, b) A necessidade de mudança de lugar teológico a partir da realidade das culturas religiosas afro-indígenas, c) A contribuição da teologia feminista da libertação para o debate do pluralismo religioso. Diante do pluralismo religioso, faz-se necessária para a teologia das religiões uma atenção especial à articulação entre a capacidade de diálogo dos grupos religiosos, não obstante as suas ambiguidades, e os desafios em torno da defesa dos direitos humanos e da sustentabilidade da vida em geral e das lógicas inclusivas que podem reger o presente século.

\section{Os processos de privatização das experiências religiosas}

Ao olhar mais detidamente para o quadro religioso brasileiro, verifica-se que há um crescente número de pessoas que desejam a experiência da fé sem a necessidade de submissão às instituições religiosas ou mesmo sem adesão forte à vivência religiosa comunitária (TEIXEIRA \& MENEZES, 2013). Na fé privatizada, cada pessoa escolhe no que deseja crer, onde e como exercer a experiência religiosa, não obstante os instrumentos e mecanismos ideológicos e massificantes que marcam esse cenário.

O quadro religioso tem apresentado tais características e tem sido fortemente marcado por elementos de massificação e de reprodução de formas individualistas, intimistas e com lógicas consumistas, de ascensão social e de prosperidade econômica e material no âmbito individual e familiar. As práticas de marketing, em geral aliadas aos interesses do sistema econômico, apropriam-se de discursos religiosos para seus fins e vice-versa. Assim, muitas pessoas passam a viver a experiência religiosa apenas ou preponderantemente com o recurso do rádio, da TV e da internet. Não obstante isso, ao mesmo tempo, diversas formas 
religiosas comunitárias se mantêm ou ressurgem com vínculos e compromissos sociais dentro de uma linha de humanização e de transformação social que vise à cidadania, à conquista de direitos, à sustentabilidade ecológica e a demais aspectos da perspectiva de justiça social.

Sobre o processo de revigoramento religioso atual, há um outro aspecto relevante. Trata-se da influência na vivência religiosa de aspectos não explicitamente religiosos que formaram a mentalidade da sociedade moderna no final do século XX, como é o caso das ênfases no consumo, na vida privada, na ascensão social e aspectos similares. Talvez isto explique, pelo menos em parte, o sucesso no Brasil dos livros e ideias de autores bastante difundidos como Paulo Coelho e Lair Ribeiro, entre outros. Nesse sentido, destacam-se também as “religiões de mercado", bastante evidenciadas em propostas no campo pentecostal, tanto nas versões protestantes como nas católico-romanas.

Não é somente no campo cristão que esse fenômeno se manifesta. Diferentes religiões, incluindo as de matriz afro-brasileira, possuem vertentes que advogam formas de uma "espiritualidade de consumo". Nelas reside um caráter intimista, individualista e marcado pela busca de respostas imediatas para problemas pessoais ou familiares concretos, que se revela na troca de esforços humanos (ofertas materiais e financeiras, atos religiosos como orações, bênção de objetos materiais e outros) por um retorno favorável aos desejos e necessidades humanas por parte do divino. Uma simples observação dos meios de comunicação social possibilita constatar o aumento do número de programas que utilizam os sistemas “o80o" e “ogoo" para fins religiosos.

Nestor Canclini já nos alertara que as identidades não mais se definem fundamentalmente por essências a-históricas, mas são criadas e recriadas pelo consumo e pelas posses materiais. A cultura torna-se desterritorializada. Ela passa a ser um processo multinacional, uma "articulação flexível de partes", uma “colagem de partes” independentemente de país ou território, religião ou ideologia (CANCLINI, 1996, p. 17). 
É necessário destacar também que o processo de secularização vivido em meio à modernidade não produziu, como se esperava, o desaparecimento ou a atenuação das experiências religiosas. Ao contrário, no campo cristão, por exemplo, que é majoritário no Brasil, as formas pentecostais e carismáticas ganharam apego popular, espaço social e base institucional, tanto no mundo evangélico como no católico. Outras religiões também vivenciam, no Brasil e no mundo, momentos de reflorescimento.

Consideramos que a secularização é facilitadora das expressões religiosas. No Brasil, por exemplo, há, como já referido, um simultâneo crescimento de pessoas sem religião e o florescimento do fervor religioso. Isso pode ser computado aos processos de secularização, entendidos não como entrave ao religioso, mas como um novo perfil cultural. Isso ocorre concomitantemente às mudanças no sistema de cristandade que, devido às influências dos processos de secularização e das opções religiosas, perdeu sua antiga dominação coercitiva sobre o espectro sociocultural. Assim, o fenômeno religioso é redimensionado na afirmação da subjetividade, não mais sob a tutela da cristandade, permitindo o livre acesso à opção e à diversidade religiosa.

É fato que há a tendência ambígua da perda de força do que se chamou "grandes instituições religiosas", vivida simultaneamente em meio ao fortalecimento dos movimentos religiosos. Para isso, há de se compreender o sentido da antiga e conhecida tensão entre instituição e movimento. A instituição religiosa é uma forma de organização em que há um conjunto de regras e regulamentos que levam um determinado grupo a construir uma identidade por meio de segmento hierárquico e de um corpo doutrinal que o caracteriza diante de outros. O movimento religioso tem como características a presença de líderes, as estruturas e a flexibilidade diante dos regulamentos estabelecidos.

$\mathrm{Na}$ atualidade, as instituições religiosas tradicionais perdem espaço. Isso acontece em razão da não mobilidade delas frente à dinâmica da busca intensa de 
respostas imediatas para as pessoas e à excessiva preocupação com a manutenção de sua pretensa identidade ou de um rigor moral apregoado como mantenedor da ordem social. Por conseguinte, a sociedade se torna cada vez mais heterogênea e já não comporta mais uma via única de regras baseada em argumentos, muitas vezes, considerados obsoletos. Entretanto, os movimentos religiosos que, via de regra, não têm o peso de um engessamento institucional, ganham pela praticidade e pela não necessária preservação de uma identidade institucional, embora em boa parte dos casos sejam regidos por uma lógica rígida de valores morais e reproduzam contradições das instituições religiosas clássicas.

Outro aspecto é o primado da experiência, sobretudo sensorial, no campo religioso atual. A realidade hoje reconstrói o valor da experiência, fruto do pensamento moderno iluminista. $\mathrm{Na}$ atualidade, as formas de espiritualidade são cada vez menos orientadas por uma adesão formal a um conjunto de verdades estabelecidas por uma autoridade eclesiástica, mas, sim, por uma subjetividade influenciada por uma cultura das mídias na qual importam mais as sensações do que os valores e a memória histórica. O viés comunitário dá lugar à ênfase na experiência individualista, por vezes até mesmo hedonista e de caráter intimista e privado.

É de fundamental importância a análise do papel das mídias na divulgação e propaganda das diferentes formas religiosas e os simultâneos processos de padronização delas. A constatação de que vivemos em uma sociedade midiática, a qual constitui um forte poder de persuasão, é notória. Nesse sentido, o papel das mídias tem servido para divulgação de diversas formas culturais, nas quais a religiosidade possui presença garantida. "A mídia, com a linguagem própria e a lógica econômica que a caracterizam, já é a maior fonte de informações sobre a religião. Os shows-missas e os shows gospel, as transmissões sobre o Papa e sobre festas religiosas são as formas explícitas disso" (MOREIRA, 2008, p. 31).

Nesse sentido, é possível afirmar que os meios de comunicação têm servido 
como ferramenta de explicitação do pluralismo religioso. Isto é, aparentemente teríamos uma "democratização" dos espaços das religiões na mídia. Contudo, as práticas não garantem a efetivação dessa mesma pluralidade, uma vez que a presença religiosa, pela ação das mídias, requer certa conformidade com a lógica do capitalismo, com a qual tem estreita relação.

Aqui, portanto, aparece uma forte tendência: todos esses aspectos, devido ao reforço do individualismo e a pouca ou quase nula ênfase na solidariedade humana e na sensibilidade comunitária e coletiva para as questões sociais, parecem não favorecer a relação entre experiência religiosa e a luta pelos direitos humanos.

\section{Teologia ecumênica e direitos humanos.}

Nossas análises mostram que o quadro sociorreligioso brasileiro não favorece, pelo menos em suas perspectivas hegemônicas, a democracia e as perspectivas mais sólidas de defesa dos direitos humanos. Diante dele, nossas reflexões se dão, em parte, como resposta à realidade sociocultural na qual, nas últimas décadas, encontramos maior visibilidade da diferença religiosa, no Brasil e no mundo, e maior intensidade no debate sobre religião e democracia, especialmente os temas ligados à laicidade do Estado.

Reforça tais preocupações o fato de, ao mesmo tempo, termos de forma ambígua e simultânea situações conflitivas e busca de diálogo entre grupos religiosos distintos em diferentes áreas da vida social. O mesmo se dá com os processos de avanço ou de limitação dos direitos humanos, que é algo bastante presente na sociedade e sustentado por diferentes grupos. Em tais processos, notase uma compreensão distinta dos mesmos direitos. Além disso, também ganha nitidez no Brasil o número de pessoas que se declaram “sem-religião”, o que reforça a agenda temática da laicidade do Estado e questões afins. 
Os esforços em direção à conquista e à defesa dos direitos humanos e ao aprofundamento da vivência democrática estão diretamente relacionados a esse quadro complexo e nossas reflexões procuram acompanhá-lo.

\subsection{Direitos humanos contra-hegemônicos.}

A fragilidade dos direitos humanos - e deveríamos incluir os da terra, como o fazem as principais vozes teológicas no contexto latino-americano (BOFF, 2009) deve-se, no entender de Boaventura de Souza Santos (2013), à assimilação em nosso contexto de apenas uma dimensão de tais direitos. Trata-se apenas daqueles estabelecidos pela democracia liberal formal, que, por sua vez, foram assimilados pelos processos de globalização econômica hegemônica. Encontram-se aí direitos individuais, processos eleitorais, fim institucional da escravidão e dos colonialismos, liberdade religiosa e outras conquistas. No entanto, os processos de globalização hegemônica, nos quais os interesses econômicos e geopolíticos das elites prevalecem, entram por vezes em turbulência. Isso ocorre quando a "zona de contato" entre eles e as situações mais degradantes da vida revela os conflitos mais agudos, como as mínimas condições de existência e situações graves de violência e opressão social.

O campo religioso, com toda a sua pluralidade, situa-se no turbilhão dos conflitos sociais e está assentado na tensão entre globalização hegemônica e globalização contra-hegemônica. Basta lembrar que a primeira, "a globalização neoliberal, prossegue com o projeto imperial global, baseado em princípios claramente ocidentais e cristãos inteiramente congruentes com os direitos humanos convencionais" (SANTOS, 2013, p. 78). E a segunda, a globalização contra-hegemônica, dá-se com a participação efetiva de grupos religiosos, que encontram em suas diferentes bases doutrinárias justificativas para uma inserção social crítica ao sistema. 
Entre os resultados dos processos hegemônicos estão: (i) a autonomia individual e privada no campo da economia e da política, o que inverte os interesses comuns da sociedade em interesses privados; (ii) uma separação dualista e de especulação abstrata entre imanência e transcendência; (iii) um processo de secularização que separa igreja e Estado, e religião e economia, mas que confere aos últimos - Estado e economia - um caráter de onipotência divina; (iv) um processo de dessacralização, com a separação entre natureza e sociedade, sendo que a primeira torna-se totalmente sujeita à segunda; (v) uma crença irredutível no progresso, como se fosse sinônimo de salvação; e (vi) a distinção entre o espaço público e o privado, reduzindo a religião à esfera do privado.

Para uma visão dos direitos humanos dentro de uma lógica de globalização contra-hegemônica, em que as religiões estão igualmente envolvidas, há que se buscar as raízes do "contrato social" que a modernidade produziu. Elas se encontram perdidas no leque de opções que a sociedade faz sob a égide da autonomia complacente dos interesses econômicos. Na visão do autor

\begin{abstract}
Assim deve ser lido o movimento neoliberal de recuo em relação ao contrato social, e em direção ao contratualismo individualista e possessivo. Assim, o movimento fundacional do estado de natureza para a sociedade civil, inscrito na teoria política liberal, que se pensava ser irreversível, revela-se afinal reversível. Grupos sociais cada vez mais vastos que são expulsos do contrato social (pós-contratualismo) ou que a ele não tem sequer acesso (pré-contratualismo) tornam-se populações descartáveis. Sem direitos mínimos de cidadania são, de fato, lançados num novo estado de natureza, a que chamo de fascismo social (SANTOS, 2013, p. 86).
\end{abstract}

As visões teológicas de diferentes religiões que se constituíram a partir da crítica ao projeto hegemônico de dominação social e econômica, como as teologias da libertação, feministas, pluralistas e progressistas, têm elaborado proposições em torno de novas perspectivas para a sociedade, que levem em conta uma visão mais aprofundada, e não apenas formal, da democracia e dos direitos humanos e da terra. Trata-se de um caminho em busca da promoção dos direitos humanos, 
econômicos, sociais, culturais e ambientais (DHESCA). Há diferentes e significativos movimentos ecumênicos na atualidade, intra-cristãos e interreligiosos, que têm se debruçado em experiências práticas nessa direção.

No Brasil, mesmo em meio às fragilidades comuns dos movimentos sociais e ecumênicos, surge a criação de redes inter-religiosas para ação conjunta em favor dos direitos humanos e da cidadania. Vivencia-se também o reflorescimento das juventudes no contexto do movimento ecumênico - que é centenário -, a formação de novas lideranças e a presença cada vez mais diversificada de grupos religiosos distintos na esfera pública. Esta irrupção ecumênica pode e deve estar relacionada com um "ecumenismo confessional", de tom mais eclesiástico ou oficial, mas permanece além, transpassando estas iniciativas mais doutrinais, construindo-se como outro espaço de espiritualidade e de incidência pública, não tão relacionado às práticas institucionais, mas às ações pessoais e comunitárias.

A espiritualidade ecumênica, como sabemos, requer capacidade de diálogo e profunda sensibilidade para a afirmação da vida e a para a promoção da paz com justiça. Nessa perspectiva, a missão cristã consistiria em anunciar o Evangelho que se fez carne em determinada cultura. Mas, nem o Evangelho e nem as culturas existem por si mesmos. Esses dois polos interagem e, com isso, o Evangelho confere à missão um aspecto profético, compreendido como Reino de Deus que, por sua vez, requer transformação crescente da sociedade e das culturas nela inseridas. Nesse sentido, do ponto de vista da fé cristã um caminho alternativo deverá ter, entre outras, três características: "apoio à vida, experiência de vida em comunidade e consciência da transcendência" (AMALADOSS, 2000, p. 150).

As referências às práticas religiosas de "apoio à vida" e às "experiências de vida em comunidade" são, obviamente, genéricas e não garantem, diretamente, força contra-hegemônica na sociedade. Há uma série de indagações sobre as práticas religiosas cujo perfil está em torno da vivência das ações solidárias, assistenciais e de promoção humana sem o caráter politizado no tocante à crítica 
do sistema econômico. Nas diferentes religiões, é possível encontrar práticas com esse perfil. No caso do Brasil, os grupos religiosos mais numerosos - católicos, evangélicos e espíritas - praticam formas de serviço social, atividades de "missão integral", espiritualidade corporativa, apoio à população de rua, idosos, crianças e atividades similares. Tais práticas se constituiriam forças contra-hegemônicas na sociedade? Ou elas seriam formas de manutenção do poder econômico hegemônico com ares mais humanizados?

Tais perguntas são de difícil equacionamento. Mesmo porque tais práticas, em geral, são vividas em meio a doses fortes de autodoação, despojamento e espírito humanitário. Uma das indicações que poderíamos seguir é que "o potencial contra-hegemônico das teologias progressistas reside na articulação que buscam entre a ligação visceral de um gesto assistencial, de um cuidado incondicional, e a luta política contra as causas do sofrimento como parte da tarefa inacabada da divindade" (SANTOS, 2013, p. 121).

\subsection{Paz, justiça e democracia.}

A perspectiva dialógica entre as religiões não elimina a dimensão crítica entre elas. Ao contrário, ela pode estimular e favorecer um ambiente de identificação das limitações de cada uma delas, para revisão de posturas dos diferentes grupos religiosos e, como isso, a promoção dos valores humanos e ações em favor do bem-estar de todas as pessoas e grupos.

Tendo em vista uma visão crítica em relação às práticas religiosas, Boaventura de Souza Santos, entre vários elementos, destaca o reforço do autoritarismo e da violência que determinados grupos religiosos fazem. 
Tanto nas versões hegemônicas da modernidade ocidental como nas teologias políticas fundamentalistas, em geral, o autoritarismo alimentase do encolhimento do espaço público e da crise do Estado, reforçando-os. A conversão toma prioridade em relação à conversação. De novo, apesar de muitas diferenças que os separam, a modernidade ocidental hegemônica e as teologias fundamentalistas islâmicas e cristãs revelam dinâmicas destrutivas que se manifestam através de novos extremismos. Os seus nomes são, entre outros: guerra, jihad, terrorismo, guerra ao terror, terrorismo de Estado, neo assimilacionismo, mártires, bombistas suicidas, criminalização da imigração, populações descartáveis, Guantánamo, unilateralismo, guerra preventiva, direito penal do inimigo etc (SANTOS, 2013, p. 89).

Sabemos que há um nexo entre violência e religião, herdado de longas tradições culturais e religiosas e que ainda marca, de alguma forma, os tempos atuais. No entanto, e não obstante a isso, há uma série de elementos dentro das próprias dinâmicas e conceituações religiosas que são geradores da paz. E daí surgem diferentes desafios e possibilidades. Um dos mais fecundos é o da 'escuta'; saber ouvir o diferente. Trata-se da "tentativa de nos submeter à verdade onde quer que ela se encontre, aceitando o pluralismo de perspectivas e de nomes, quaisquer que eles sejam e onde quer que pulse o coração da vida. Esta missão é 'sair' da violência mimética e redutora da alteridade do outro e entrar numa dinâmica de paz polifacética e plural” (BINGEMER, 2001, p. 288).

Portanto, o quadro de pluralismo religioso não deve ser compreendido apenas em sua clivagem vertical, na qual as diferentes religiões são listadas e conhecidas. Ele deve, sobretudo, ser discernido em suas linhas horizontais, que perpassam diferentes experiências religiosas e que, invariavelmente, distinguem-se por critérios e razões ideológicas e políticas. Nesse intercruzamento religioso se dão movimentos os mais diversos, ora tendendo aos processos de globalização hegemônica, para se usar a linguagem de Boaventura de Souza Santos, ora reforçando os processos de globalização contra-hegemônicos.

Nossa proposição é que a perspectiva ecumênica, uma vez articulada com as dimensões sociais, políticas, econômicas e culturais, dentro dos variados contextos históricos, pode oferecer densidade e amplitude para a reflexão teológica e para as 
práticas de promoção dos direitos humanos e da democracia. Os esforços que valorizam a capacidade de diálogo e de sensibilidade ecumênica e aqueles que destacam a importância pública das religiões partem da concepção de que a perspectiva ecumênica, tanto em nível prático quanto em nível teóricometodológico, requer e possibilita uma compreensão mais apurada da realidade, um aperfeiçoamento de visões dialógicas e o cultivo de maior sensibilidade para a valorização da vida, em especial a dos pobres, e para a promoção da paz e da justiça.

No campo da defesa dos direitos humanos e da terra, a vivência de uma espiritualidade integradora pode constituir-se em uma singular contribuição. Isso pode se dar em nível religioso explícito ou não, em formas institucionais ou de caráter mais espontâneo. Para isso, torna-se imprescindível o diálogo entre visões religiosas ocidentais e orientais, incluindo as visões africanas e asiáticas, que advogam a convicção de que os aspectos materiais e imateriais da vida não podem ser dualisticamente separados. A integração da espiritualidade deve dar-se igualmente no tocante às situações que envolvem a vida humana, tais como os olhares masculino e feminino, e homo e heterossexuais. Da mesma forma, o diálogo inter-religioso deve contemplar as formas de serviço e compaixão com o sofrimento humano e as ações e manifestações públicas de protesto e contestação da injustiça social.

As lutas contra-hegemônicas pelos direitos humanos visam a mudança das estruturas sociais que são responsáveis pela sistemática de sofrimento injusto. São lutas materiais no sentido em que o seu ímpeto político deve dirigir-se à economia política subjacente à produção e à reprodução de relações sociais desiguais, mesmo quando essas relações estão menos direta ou linearmente ligadas à exploração capitalista e a uma hierarquia de base classista, como é o caso das relações que são objeto da política identitária convencional (discriminação sexual, racial, étnica, religiosa). São também lutas materiais no sentido em que pressupõem recursos políticos, financeiros e humanos para construir organizações e gerar militância (SANTOS, 2013, p. 134). 
Não obstante o fortalecimento institucional e popular de propostas religiosas com acentos mais sectários e verticalistas, em geral conflitivas, fechadas ao diálogo, marcadas por violência simbólica e de caráter fundamentalista, o campo religioso, como já referido, tem experimentado também formas ecumênicas de diálogo entre grupos religiosos distintos. Diante desse quadro, surgem diferentes perguntas: como tal realidade, especialmente com as suas contradições, incide no quadro social e político? Como elas interferem, mais especificamente, no fortalecimento de uma cultura democrática e de práticas afins? Qual o papel de uma espiritualidade ecumênica em um projeto de paz e de aprofundamento da democracia para as futuras gerações?

No caso da fé cristã, há várias indicações teológicas no sentido de uma revisão dos processos de evangelização. O teólogo José Comblin nos alertara que não se podem repetir as marcas de orgulho, de agressividade, de conquista e de dominação do cristianismo no passado. Uma nova atitude missionária, distanciada das forças militares, políticas, econômicas e culturais do império, deve dar base para um diálogo com as demais religiões. Trata-se de evangelizar sem superioridade de poder. Esse diálogo deve se constituir como referência para as demais questões teológicas. Para o referido autor, o diálogo advindo do pluralismo religioso precisa estar relacionado à questão da pobreza, pois ela é crucial para a fé cristã. Qual é a mensagem do cristianismo em meio a outras religiões? Em que ele se distingue? Se o cristianismo conseguir dar visibilidade à sua questão teológica primordial, prévia a qualquer exposição, que é a situação das pessoas pobres, ele poderá dar uma contribuição significativa para o diálogo inter-religioso. Será isso possível dentro do quadro social, político, econômico e religioso atual? (COMBLIN, 2005). Essas e outras perguntas similares não encontram respostas razoavelmente seguras. Há um longo e denso caminho de reflexão em direção ao amadurecimento delas. 


\section{Considerações finais}

A complexa realidade social e religiosa que hoje vivenciamos, especialmente o pluralismo religioso, desafia fortemente a produção teológica latino-americana. Entre os desafios está o aprofundamento de uma reflexão em torno da defesa dos direitos humanos e do fortalecimento e aprofundamento da democracia.

Priorizamos, em um primeiro momento, um balanço de questões que demarcam o caminho para uma teologia ecumênica das religiões, pois elas geram, direta ou indiretamente, as temáticas teológicas em torno da defesa dos direitos humanos e da democracia. Em seguida, oferecemos um panorama da tendência atual dos processos de privatização das experiências religiosas e como tal tendência não favorece propostas religiosas marcadas por responsabilidade social, especialmente na linha da defesa dos direitos humanos. Analisamos também as relações entre teologia ecumênica e direitos humanos, privilegiando o diálogo com a noção de globalização contra-hegemônica, de Boaventura de Santos Souza.

Nossa pressuposição é que os processos de emancipação humana se articulam frontalmente com as questões teológicas em torno da democracia. A valorização da pluralidade religiosa, a recuperação do sentido espiritual da gratuidade, o interesse e inclinação para se repensar categorias filosóficas e teológicas tradicionais dentro de um quadro de valorização da dignidade humana e de interfaces com as ciências e com a espiritualidade, o diálogo com tradições religiosas diferentes são elementos que, obviamente, vão além das exigências que os processos de aprofundamento da democracia nos colocam. Todavia, em todos eles há bases para se cooperar com perspectivas democráticas mais amplas e consistentes.

Procuramos mostrar que, diante do pluralismo religioso, faz-se necessária para a teologia das religiões uma atenção especial à articulação entre a capacidade de diálogo dos grupos religiosos e os desafios em torno da defesa dos direitos 
humanos, pressupondo que a espiritualidade ecumênica requer visão dialógica, profunda sensibilidade com as questões que afetam a vida humana e inclinação para a promoção da paz e da justiça. Também indicamos que uma espiritualidade ecumênica que emerge do pluralismo religioso terá como valor a dimensão de alteridade e isso incidirá nos processos religiosos e sociais, favorecendo perspectivas utópicas, democráticas e doadoras de sentido. Reconhecemos que todas essas dimensões teológicas requerem aprofundamento e estudos mais aprofundados.

Os objetivos dessa nova movimentação teológica e pastoral, em linhas gerais, residem na articulação dos elementos fundantes da teologia latinoamericana - como a sensibilidade espiritual com a defesa da vida, dos direitos humanos e da terra, especialmente os dos empobrecidos - com uma visão ecumênica, dialógica e de busca de uma fundamentação teológica do pluralismo religioso.

\section{REFERÊNCIAS}

AMALADOSS, Michael. Missão e Inculturação. São Paulo: Loyola, 2000.

BENJAMIN, Walter. O Capitalismo como Religião. São Paulo: Boitempo, 2013.

BOFF, Leonardo. Opção Terra. Rio de Janeiro: Record, 2009.

CANCLINI, Nestor. Consumidores e Cidadãos: conflitos multiculturais da globalização. Rio de Janeiro: UFRJ, 1996.

COMBLIN, José. Quais os desafios dos temas teológicos atuais? São Paulo, SP: Paulus, 2005.

HAIGHT, Roger. Jesus, símbolo de Deus. São Paulo-SP, Paulinas, 2003.

HINKELAMMERT, Franz. A Maldição que pesa sobre a lei: as raízes do pensamento crítico em Paulo de Tarso. São Paulo: Paulus, 2012.

LÖWY, Michael. A Guerra dos deuses: religião e política na América Latina. Petrópolis: Vozes, 2000. 
MOREIRA, Alberto da Silva. "O futuro da religião no mundo globalizado". In: MOREIRA, Alberto da Silva \& DIAS DE OLIVEIRA, Irene (Org.). O Futuro da Religião na

Sociedade Global. São Paulo: Paulinas/UCG, 2008

RIBEIRO, Claudio de Oliveira. Pluralismo e Libertação. São Paulo: Paulinas, 2014.

SANTOS, Boaventura de Souza. Se Deus Fosse um Ativista dos Direitos Humanos. São Paulo: Cortez Editora, 2013.

TEIXEIRA, Faustino \& MENEZES, Renata. As Religiões em Movimento: O Censo de 2010. Petrópolis: Vozes, 2013. 